\title{
Preparation, Characterization, and Cationic Functionalization of Cellulose-Based Aerogels for Wastewater Clarification
}

\author{
Yang Hu, ${ }^{1}$ Shanshan Li, ${ }^{1}$ Tanya Jackson, ${ }^{1}$ Hanna Moussa, ${ }^{2}$ and Noureddine Abidi ${ }^{1}$ \\ ${ }^{1}$ Fiber and Biopolymer Research Institute, Department of Plant and Soil Science, Texas Tech University, Lubbock, TX, USA \\ ${ }^{2}$ Department of Mechanical Engineering, Texas Tech University, Lubbock, TX, USA \\ Correspondence should be addressed to Noureddine Abidi; noureddine.abidi@ttu.edu
}

Received 1 August 2016; Revised 10 November 2016; Accepted 16 November 2016

Academic Editor: Hyung-Ho Park

Copyright (c) 2016 Yang Hu et al. This is an open access article distributed under the Creative Commons Attribution License, which permits unrestricted use, distribution, and reproduction in any medium, provided the original work is properly cited.

\begin{abstract}
Aerogels are a series of materials with porous structure and light weight which can be applied to many industrial divisions as insulators, sensors, absorbents, and cushions. In this study, cellulose-based aerogels (aerocelluloses) were prepared from cellulosic material (microcrystalline cellulose) in sodium hydroxide/water solvent system followed by supercritical drying operation. The average specific surface area of aerocelluloses was $124 \mathrm{~m}^{2} / \mathrm{g}$. The nitrogen gas $\left(\mathrm{N}_{2}\right)$ adsorption/desorption isotherms revealed type $\mathrm{H} 1$ hysteresis loops for aerocelluloses, suggesting that aerocelluloses may possess a porous structure with cylindrically shaped pores open on both ends. FTIR and XRD analyses showed that the crystallinity of aerocelluloses was significantly decreased as compared to microcrystalline cellulose and that aerocelluloses exhibited a crystalline structure of cellulose II as compared to microcrystalline cellulose (cellulose I). To perform cationic functionalization, a cationic agent, (3-chloro-2-hydroxypropyl) trimethylammonium chloride, was used to introduce positively charged sites on aerocelluloses. The cationized aerocelluloses exhibited a strong ability to remove anionic dyes from wastewater. Highly porous and low cost aerocelluloses prepared in this study would be also promising as a fast absorbent for environmental pollutants.
\end{abstract}

\section{Introduction}

Aerogels are materials having a remarkable porous structure with pores filled with air rather than liquid [1]. Typical aerogels generally present a three-dimensional network exhibiting extremely light weight and high surface area. Various materials can be used to prepare aerogels, one of which is a group of inorganic aerogels, such as $\mathrm{SiO}_{2}, \mathrm{Al}_{2} \mathrm{O}_{3}$, $\mathrm{TiO}_{2}, \mathrm{ZrO}_{2}, \mathrm{MgO}$, and their composites, which have been extensively studied $[2,3]$. The preparation of aerogels involves a "sol-gel" process described by a series of successive steps including solvent dispersion of polymers or particles, gelation of material mixture under thermal or mechanical condition, and supercritical dehydration [4]. Aerogels have been broadly employed as thermal insulators, catalysts, sensors, absorbents, drug carriers, and other applications due to their appealing properties [5-9].

Cellulose is one of the most abundant bioorganic materials in nature. It is a biopolymer consisting of D-glucose repeating units. The degree of polymerization (DP) of cellulose can vary from 300 to 15,000 depending on the source of cellulose [10,11]. Cellulose is stable, nontoxic, biodegradable, and inexpensive. Due to its high molecular weight and stable crystalline structure, cellulose is very difficult to dissolve in most common solvents. Only a few solvents, such as sodium hydroxide/urea/water, lithium chloride/N,Ndimethylacetamide (LiCl/DMAc), N-methyl-morpholine- $\mathrm{N}$ oxide (NMMO), and ionic liquids (ILs), are able to swell and dissolve cellulose [12]. The effective dissolution of cellulosic macromolecules is the predominant step to prepare cellulosebased aerogels (aerocelluloses) and develop value-added materials with well-defined architectures.

Aerocelluloses are one of the most valuable and environmentally friendly products that are derived from cellulosic materials. They were first developed using cellulose acetates dissolved in acetone followed by gelation and supercritical drying processes and the resultant aerocelluloses exhibited a fairly high specific surface area $\left(\sim 300 \mathrm{~m}^{2} / \mathrm{g}\right)$ [13]. Other aerocelluloses were developed, form microcrystalline cellulose, by dissolving it in calcium thiocyanate, followed by 
being gelatinized and dehydrated by solvent exchange drying to achieve a porous structure with a specific surface area of $190 \mathrm{~m}^{2} / \mathrm{g}$ [14]. By using supercritical drying method and the NMMO solvent, the aerocelluloses prepared from microcrystalline cellulose could achieve a higher specific surface area $\left(400 \mathrm{~m}^{2} / \mathrm{g}\right)$ [15]. Likewise, dissolving microcrystalline cellulose in $\mathrm{NaOH} /$ water solvent system led to aerocelluloses with a high specific surface area $\left(300 \mathrm{~m}^{2} / \mathrm{g}\right)$ and a low density $\left(0.06 \mathrm{~g} / \mathrm{cm}^{3}\right)$ [16]. In addition to supercritical drying, the freeze-drying was also used to prepare porous cellulose materials which can be denoted as cryogels. By using both calcium thiocyanate and $\mathrm{LiCl} / \mathrm{DMAc}$ solvents, the surface area of cellulose cryogels could achieve around $160 \mathrm{~m}^{2} / \mathrm{g}$ [17]. Both aerocelluloses and cryogels could exhibit a light weight ranging from 116 to $350 \mathrm{~kg} / \mathrm{cm}^{3}$ [18].

In this study, we prepared aerocelluloses using a "solgel" process by dissolving MCC in $\mathrm{NaOH}$ /water solvent system followed by gelation and supercritical drying operations. Furthermore, we employed (3-chloro-2-hydroxypropyl) trimethylammonium chloride to functionalize the asprepared aerocelluloses to immobilize negatively charged dye molecules for wastewater clarification. Wastewater containing dye-contaminating molecules can lead to serious environmental problems [19]. Various methods have been developed to remove dye molecules from wastewater [20, 21]. Some biogenerated polymers have been also used as active reagents for wastewater treatment, such as starch-derived carbon aerogels, chitosan, and its derivatives [19, 22]. Due to the high surface area of aerocelluloses as well as the low cost, cationized aerocelluloses could be a candidate for wastewater clarification.

\section{Experimental}

2.1. Materials. Cellulose (Microcrystalline Cellulose, MCC, Avicel ${ }^{\circledR}$ PH-102 NF) was obtained from FMC BioPolymer (Newark, DE, USA). Sodium hydroxide $(\mathrm{NaOH}$, Cat. number S318-500) was purchased from Fisher Chemical (Fisher Scientific, USA) and sulfuric acid $\left(\mathrm{H}_{2} \mathrm{SO}_{4}\right.$, Cat. number LC255503) was purchased from LabChem (Zelienople, PA, USA). CR-2000 (3-chloro-2-hydroxypropyl trimethylammonium chloride, CAS number 0003327-22-8) was obtained from Dow Chemical (Midland, MI, USA) and abbreviated as CHPTAC. Color Index Reactive Blue 19 (CI RB19) dye (Drum number 472308 1/0) was purchased from Organic Dyestuffs Corporation (East Providence, RI, USA). All chemicals were used without further purification except $\mathrm{H}_{2} \mathrm{SO}_{4}$ which was bone dried to ensure its purity of $99.9 \%$ with lower than $10 \mathrm{ppb}$ of water prior to use.

2.2. Preparation of Aerocelluloses. Cellulose was dissolved in $\mathrm{NaOH} /$ water solvent system at different concentrations (5, 9, and $11 \%, w / w)$ as shown in Table $1 . \mathrm{NaOH}$ was first dissolved in deionized (DI) water and precooled at $-12^{\circ} \mathrm{C}$ for $2 \mathrm{~h}$ and cellulose was dispersed in DI water and stirred at $5^{\circ} \mathrm{C}$ for $2 \mathrm{~h}$. Next, the cellulose/water solution was mixed with $\mathrm{NaOH}$ solution and the mixture was placed in $-12^{\circ} \mathrm{C}$ freezer. The mixture was stirred for $30 \mathrm{~s}$ every $5 \mathrm{~min}$ for $1 \mathrm{~h}$ to homogenize the mixture. The resulting cellulose/ $\mathrm{NaOH} /$ water mixture
TABLE 1: Mass ratio of cellulose and solvent system (w/w) used for dissolution.

\begin{tabular}{lccc}
\hline Cellulose\% & 5 & 9 & 11 \\
\hline Avicel $(\mathrm{g})$ & 5.0 & 9.0 & 11.0 \\
$\mathrm{NaOH}(\mathrm{g})$ & 7.6 & 7.6 & 7.6 \\
Water $(\mathrm{g})$ & 87.4 & 83.4 & 81.4 \\
\hline
\end{tabular}

was transferred to cylindrical molds with an approximate dimension of 16-20 mm diameter and 30-40 $\mathrm{mm}$ high, and placed in an oven at $50^{\circ} \mathrm{C}$ for $2 \mathrm{~h}$ to form a gel. The cylindrical gels were then regenerated in distilled water, neutralized with $0.1 \mathrm{M} \mathrm{H}_{2} \mathrm{SO}_{4}$, and rinsed with $\mathrm{DI}$ water to remove sulfuric acid. The solvent exchange of gels with pure acetone was performed once every $2 \mathrm{~h}$ for $48 \mathrm{~h}$ to ensure complete replacement of water with acetone. Afterwards, the carbon dioxide $\left(\mathrm{CO}_{2}\right)$ supercritical drying was used to dehydrate the gels in a Jumbo Critical Point Dryer (SPI Supplies, West Chester, PA, USA) equipped with a water jacket for cooling and heating (Thermo Scientific NesLab-RTE 10, Newington, $\mathrm{NH}$, USA). The supercritical drying was first performed at $10^{\circ} \mathrm{C}$ under $5 \mathrm{MPa}$ with liquid $\mathrm{CO}_{2}$, and the excess acetone was purged intermittently for $30 \mathrm{~s}$ at the same pressure and temperature until the gels were filled with liquefied $\mathrm{CO}_{2}$ instead of acetone. Next, the supercritical drying system was pressurized to $8 \mathrm{MPa}$ and the temperature was increased to $35^{\circ} \mathrm{C}$ to dehydrate the gels for approximately $3 \mathrm{~h}$. When the total amount of the interstitial liquefied $\mathrm{CO}_{2}$ was removed, the system was slowly depressurized and the supercritical dryer was cooled down to collect the aerocelluloses.

2.3. Material Characterization. The aerocelluloses were characterized by Scanning Electron Microscopy (SEM) Surface Porous Profile Analysis, Fourier Transform Infrared Spectroscopy (FTIR), Thermogravimetric Analysis (TGA), and Xray Diffraction (XRD). SEM observation of the aerocelluloses was performed in an environmental SEM (Hitachi TM-1000, Pleasanton, CA, USA). SEM samples were placed on carbon tape attached to the SEM sample stage. The cross sections of aerocelluloses prepared by $5 \%, 9 \%$, and $11 \%$ cellulose concentrations were analyzed.

The pore size, the pore size distribution, and the specific surface area measurements were performed by Gemini $2390 \mathrm{t}$ (Micromeritics, Norcross, GA). All the data were obtained using Brunauer-Emmett-Teller (BET) surface area analysis and Barrett-Joyner-Halenda (BJH) pore size and volume analysis. The samples were ground in the mortar by a pestle, and then they were degassed at $90^{\circ} \mathrm{C}$ for $22 \mathrm{~h}$. The data were analyzed based on the $\mathrm{N}_{2}$ adsorption/desorption isotherms, surface area parameters, and curves of pore size versus pore volume of different aerocellulose samples.

FTIR equipped with a Universal Attenuated Total Reflectance (UATR) accessory (Perkin Elmer Spectrum-400, Waltham, MA) was used to acquire the FTIR spectra of aerocellulose samples. Cellulose and aerocellulose samples were first placed in an environmentally controlled laboratory maintained at a relative humidity of $65 \pm 2 \%$ and $21 \pm$ $1^{\circ} \mathrm{C}$ at least $48 \mathrm{~h}$ prior to analysis. The FTIR spectra were 


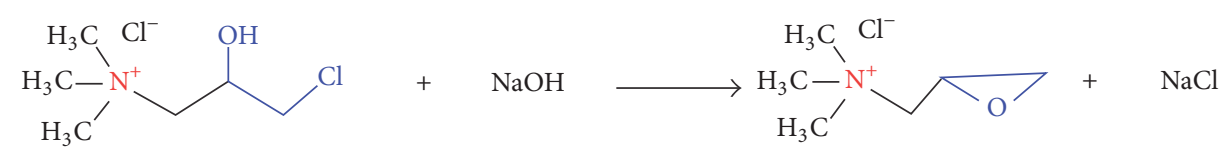

(a)

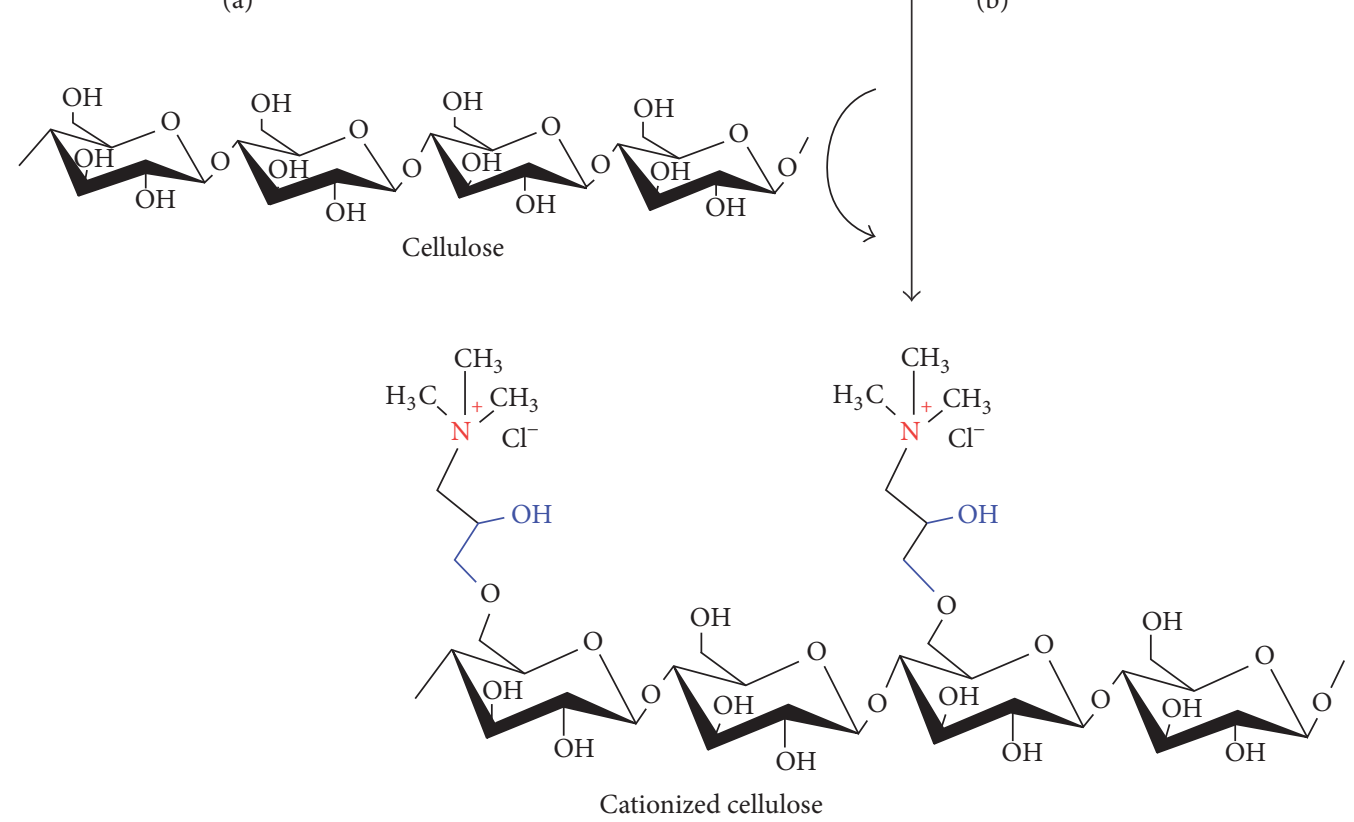

ScHEme 1: Schematic reaction route of cationic functionalization of aerocelluloses: (a) (3-chloro-2-hydroxypropyl) trimethylammonium chloride (CHPTAC); (b) 2,3-epoxypropyltrimethyl ammonium chloride (EPTAC).

then recorded at a spectra resolution of $4 \mathrm{~cm}^{-1}$ with 32 coadded scans over the range from 650 to $4000 \mathrm{~cm}^{-1}$. Perkin Elmer software was used to perform spectra normalization, baseline corrections, and peak integration. FTIR spectra were also subjected to Principal Component Analysis (PCA) with leverage correction and mean-center cross validation boxes checked using Unscrambler V. 9.6 Camo Software AS (CAMO Software AS, Norway).

Thermogravimetric analysis of cellulose and aerocellulose samples were performed using Pyris1TGA (PerkinElmer Shelton, CT, USA). Samples were also placed in an environmentally controlled laboratory at relative humidity of $65 \pm 2 \%$ and $21 \pm 1^{\circ} \mathrm{C}$ at least $48 \mathrm{~h}$ prior to testing. Thermograms were recorded between $37^{\circ} \mathrm{C}$ and $600^{\circ} \mathrm{C}$ with a heating rate of $10^{\circ} \mathrm{C} / \mathrm{min}$ in a flow of nitrogen at $20 \mathrm{~mL} / \mathrm{min}$. Pyris software was used to calculate the first derivatives of the thermograms (DTC), the percentages of weight loss, and the decomposition temperatures.

The crystalline structures of cellulose and aerocellulose samples were analyzed using SmartLab system (Rigaku Corporation, Model HD 2711N). XRD was performed using $\mathrm{CuK} \alpha$ radiation $(\lambda=0.15406)$ generated at $40 \mathrm{kV}$ and $44 \mathrm{~mA}$. Scans were conducted between $10^{\circ}$ and $50^{\circ}$ two-theta in $2^{\circ}$ stepwise per minute.

2.4. Cationic Functionalization of Aerocelluloses. Aerocellulose samples were placed in beakers with $30 \mathrm{~mL}$ of DI water containing $65 \%(\mathrm{w} / \mathrm{w})$ of the cationic reagent $(1.05 \mathrm{~g} \mathrm{CR}-$ 2000). The beaker was placed on the bunch at room temperate for 5 days to allow the cationic reagent to diffuse inside the aerocellulose network. Next, $0.5 \mathrm{~g}$ of $\mathrm{NaOH}$ was added to the solution containing aerocelluloses and the cationic reagent, and the mixture was stirred until it was homogenous and remained overnight. The cationized aerocelluloses were rinsed with DI water to ensure complete removal of unreacted cationic reagent and then air-dried at room temperature. The schematic route of cationic functionalization of aerocelluloses is shown in Scheme 1. To test the absorbability of dye, the aerocellulose and cationized aerocelluloses prepared from $5 \%$ and $11 \%$ cellulose concentrations were placed in $20 \mathrm{~mL}$ of DI water containing $0.1 \mathrm{~g} / \mathrm{L}$ of CI RB19 dye. The absorbance of the solution was measured using Lambda $650 \mathrm{UV} / \mathrm{Vis}$ Spectrometer (PerkinElmer, USA) at $650 \mathrm{~nm}$.

2.5. Statistical Analysis. Experimental runs of all samples of cellulose and aerocelluloses were repeated at least for three times. The significant differences between sample groups were calculated using One-Way ANOVA (LSD, Least Significant Difference) $(p<0.05$ confident interval; IBM SPSS Statistical Software; Release 19.0.0).

\section{Results and Discussion}

3.1. Preparation and Material Characterization of Aerocelluloses. Aerocelluloses prepared from different cellulose concentrations are illustrated in Figure 1. The aerocellulose prepared from 5\% cellulose concentration appears to be fluffier than aerocelluloses prepared from $9 \%$ and $11 \%$ cellulose concentrations, suggesting that $5 \%$ aerocellulose may have a more porous structure. SEM images of cross section 


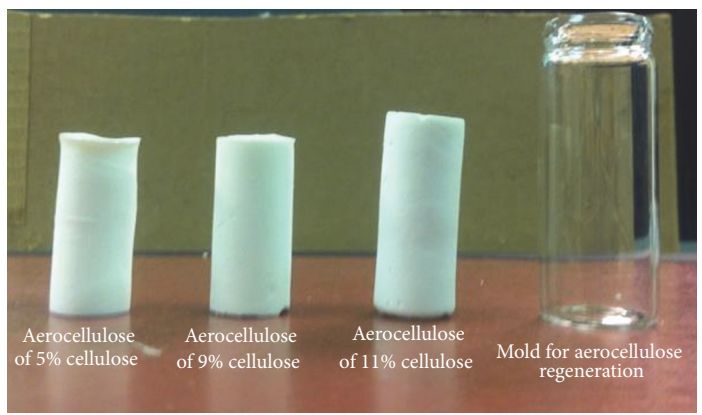

FIGURE 1: Photographs of aerocelluloses prepared from 5\%, 9\%, and 11\% cellulose concentrations.

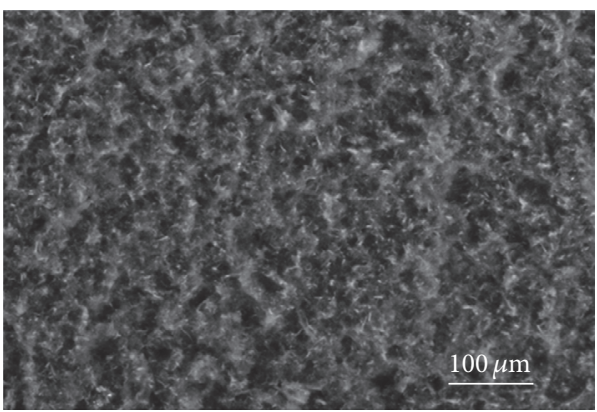

(a)

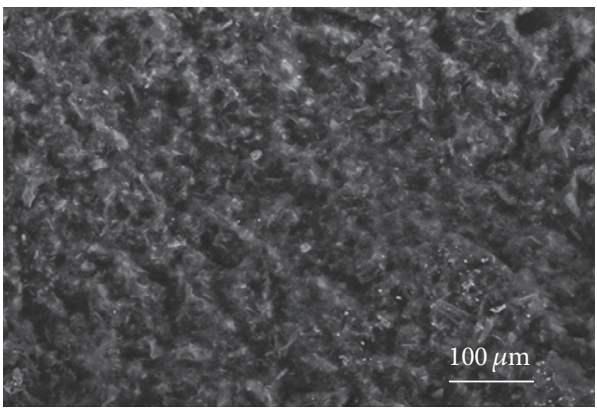

(c)

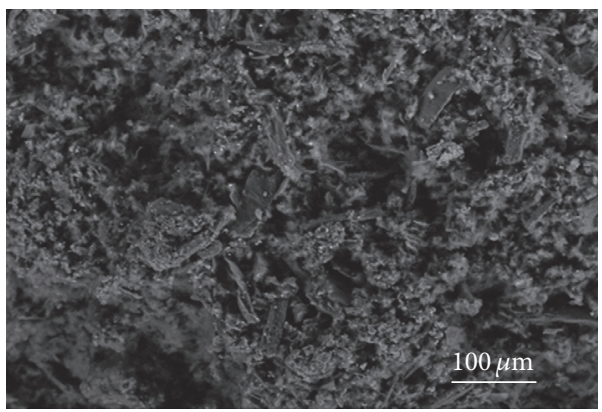

(e)

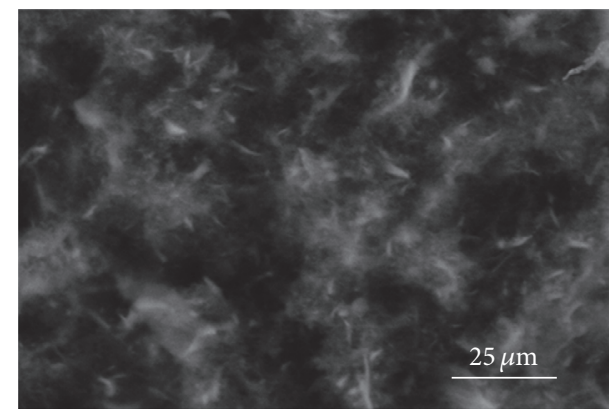

(b)

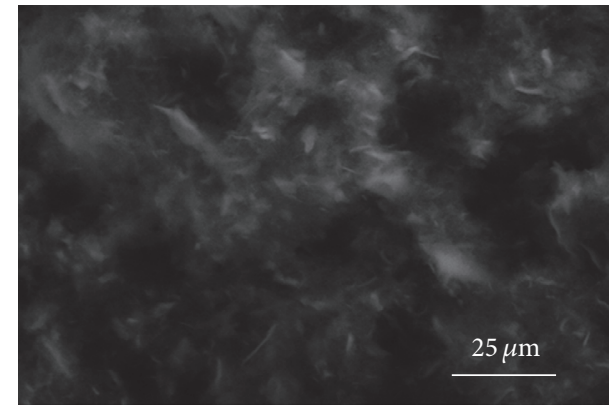

(d)

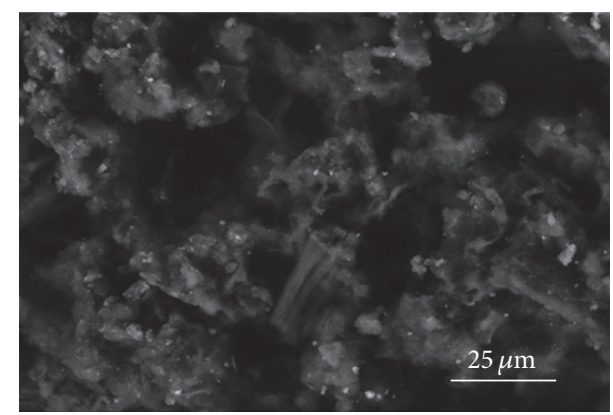

(f)

FIGURE 2: SEM images of cross section of aerocelluloses prepared from different cellulose concentrations: (a-b) 5\%, (c-d) 9\%, and (e-f) 11\%. Images of (b), (d), and (f) are images at a higher magnification of (a), (c), and (e), respectively.

of aerocelluloses are shown in Figure 2. At low magnification, aerocelluloses prepared from $5 \%$ and $9 \%$ cellulose concentrations have similar porous morphologies, whereas aerocellulose from $5 \%$ cellulose concentration exhibits more uniform pores aligned in an ordered arrangement that can be observed at high magnification (Figure 2(b)). Comparably, the aerocellulose prepared from $11 \%$ cellulose concentration exhibits a more compact structure with much more irregular pores shown at low magnification and more open pores shown at high magnifications. It is noticed that some visible 


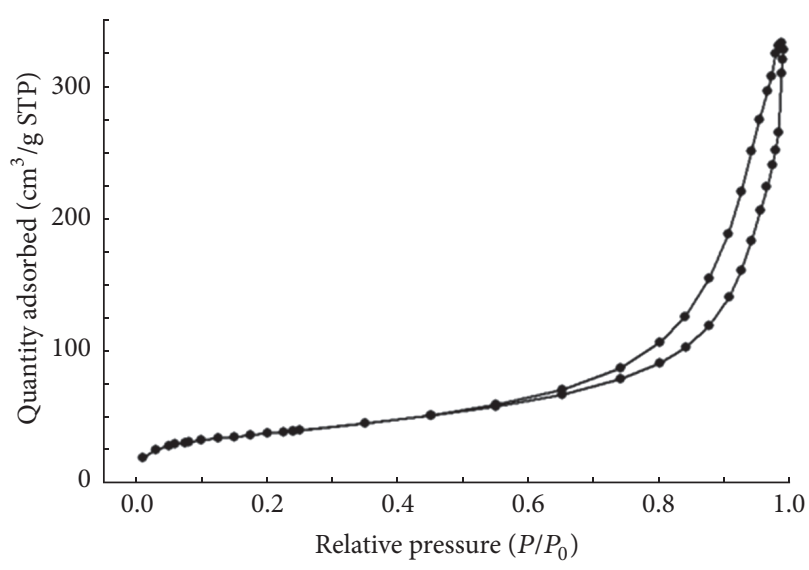

(a)

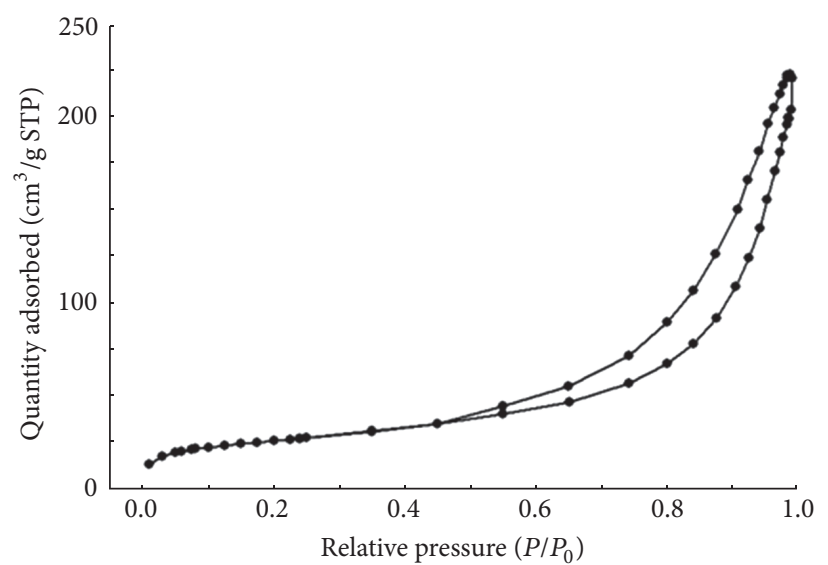

(b)

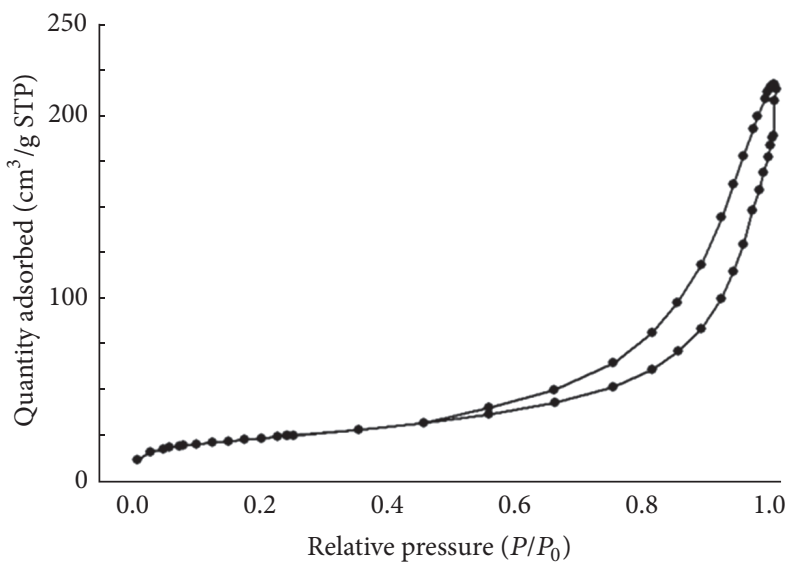

(c)

FIGURE 3: $\mathrm{N}_{2}$ adsorption/desorption isotherms of aerocelluloses prepared from different cellulose concentrations: (a) 5\%; (b) $9 \%$; (c) 11\%.

chunks and small white aggregates are present in the aerocellulose from $11 \%$ cellulose concentration, suggesting that cellulose in this case was not well dissolved, which led to inhomogeneous cellulose solution to prepare aerocellulose at this high concentration. More porous structure generally enables aerocelluloses to obtain ultra-light weight and high specific surface area, and thereby $5 \%$ cellulose concentration may be the best option to prepare aerocelluloses with satisfactory porosity in this study.

Figure 3 shows $\mathrm{N}_{2}$ adsorption/desorption isotherms for aerocelluloses prepared from 5\%,9\%, and $11 \%$ cellulose concentrations. The isotherms for three aerocellulose samples all exhibit type IV characteristics. The H1 hysteresis loops present in these isotherms reveal that both capillary condensation and evaporation occurred in a cylindrical channel, suggesting that many cylindrically shaped pores open at both ends [23-25]. Accordingly, the aerocelluloses prepared in this study are considered mesoporous materials with a pore diameter of $2-50 \mathrm{~nm}$. Table 2 summarizes the variance analysis of the surface area of aerocelluloses. These aerocelluloses exhibit high BET surface areas varying from 80 to $125 \mathrm{~m}^{2} / \mathrm{g}$. The average BET surface area of aerocelluloses prepared from $5 \%$ cellulose concentration is $124 \mathrm{~m}^{2} / \mathrm{g}$, which is significantly higher than aerocelluloses prepared from $9 \%$ and $11 \%$ cellulose concentrations $(p<0.05)$. The pore size distributions of aerocelluloses prepared from different cellulose concentrations are shown in Figure 4 and Table 3. The aerocelluloses prepared from $5 \%$ cellulose concentration exhibit higher pore volume corresponding to a higher surface area than aerocelluloses prepared from $9 \%$ and $11 \%$ cellulose concentrations. The statistical analysis shows that the amount of cellulose dissolved in the solvent system plays a key role in the surface area of the aerocellulose. The low surface area of aerocelluloses prepared from $9 \%$ and $11 \%$ cellulose concentrations may be attributed to the incomplete dissolution of cellulose at high cellulose concentrations.

The FTIR spectra of cellulose and aerocelluloses exhibit different structural characteristics (Figure 5). The vibration at $3292 \mathrm{~cm}^{-1}$ is assigned to intermolecular hydrogen bonding (C3- $(\mathrm{OH})-\mathrm{C} 6(\mathrm{O})$ ) while the vibration at $3335 \mathrm{~cm}^{-1}$ is due to intramolecular hydrogen bonding $(\mathrm{O}(3) \mathrm{H}-\mathrm{O}(5))$, which are only present in the FTIR spectrum of cellulose [26]. The conversion from MCC to aerocelluloses is accompanied by a shift of these vibrations to 3443 and $3481 \mathrm{~cm}^{-1}$. The vibration at $3443 \mathrm{~cm}^{-1}$ is assigned to intramolecular hydrogen bonding $(\mathrm{O}(2) \mathrm{H}-\mathrm{O}(6))$ and the vibration at $3481 \mathrm{~cm}^{-1}$ is assigned to the intramolecular hydrogen bonding in cellulose II $[26,27]$. The disappearance of the vibrations at 3292 and $3335 \mathrm{~cm}^{-1}$ 
TABLE 2: The average and multicomparisons of BET and Langmuir surfaces.

\begin{tabular}{lccc}
\hline Variable & & Newman-Keuls test; homogenous groups, $\alpha=0.05$ \\
& $5 \%$ aerocelluloses & 9erocelluloses & $11 \%$ aerocelluloses \\
\hline$S_{\text {BET }}$ single $\left(\mathrm{m}^{2} / \mathrm{g}\right)$ & $120.61(\mathrm{~A})$ & $77.61(\mathrm{~B})$ & $97.09(\mathrm{AB})$ \\
$S_{\mathrm{BET}}\left(\mathrm{m}^{2} / \mathrm{g}\right)$ & $124.42(\mathrm{~A})$ & $80.01(\mathrm{~B})$ & $100.17(\mathrm{AB})$ \\
$S_{\text {Langmuir }}\left(\mathrm{m}^{2} / \mathrm{g}\right)$ & $160.42(\mathrm{~A})$ & $103.13(\mathrm{~B})$ & $129.19(\mathrm{AB})$ \\
\hline
\end{tabular}

Note: $S_{\mathrm{BET}}$ single: surface area determined by BET method at single point $P / P_{0}=0.199 ; S_{\mathrm{BET}}$ : surface area determined by BET method; $S_{\mathrm{Langmuir}}$ : surface area determined by Langmuir method; A, B, and C: groups in multicomparisons.

TABLE 3: The average and multicomparisons of the pore volumes and pore diameters.

\begin{tabular}{lccc}
\hline Variable & & Newman-Keuls test; homogenous groups, $\alpha=0.05$ & \\
& 5\% aerocellulose & 9\% aerocellulose & $11 \%$ aerocellulose \\
\hline $\begin{array}{l}S_{\text {Pore }} \text { BJH }\left(\mathrm{m}^{2} / \mathrm{g}\right) \\
\begin{array}{l}\text { Cumulative } V_{\text {BJH }} \\
\left(\mathrm{cm}^{3} / \mathrm{g}\right)\end{array}\end{array}$ & $113.93(\mathrm{~A})$ & $75.73(\mathrm{~B})$ & $97.65(\mathrm{AB})$ \\
Av. pore diameter $(\AA)$ & $0.4546(\mathrm{~A})$ & $0.2798(\mathrm{~B})$ & $0.3249(\mathrm{~B})$ \\
\hline
\end{tabular}

Note: $S_{\text {Pore }}$ BJH: surface area of pores determined by the BJH method. Cumulative $V_{\mathrm{BJH}}$ : BJH adsorption cumulative volume of pores; Av. pore diameter: $\mathrm{BJH}$ desorption average pore diameter; A, B, and C: groups in multicomparisons.

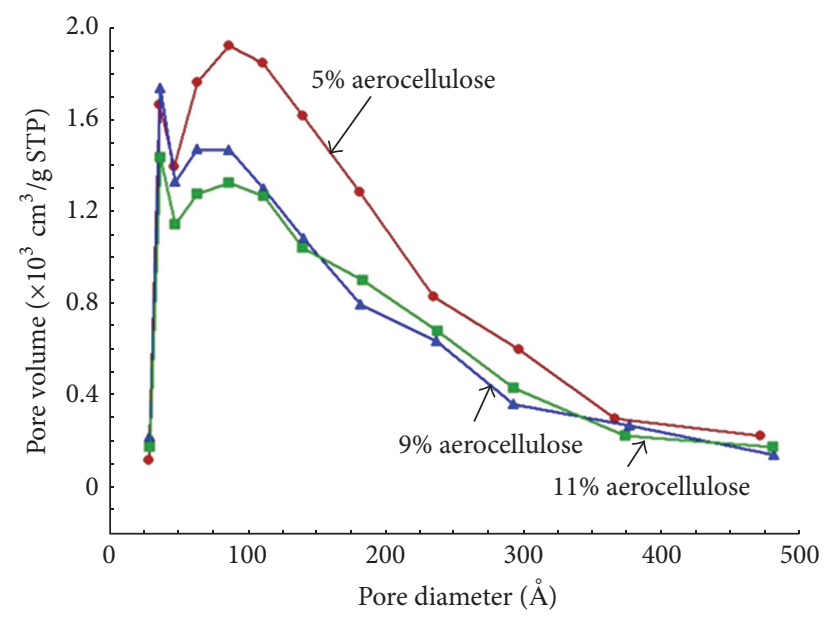

FIGURE 4: Pore size distributions of aerocelluloses prepared from $5 \%, 9 \%$, and $11 \%$ cellulose concentrations.

and the appearance of the vibrations at 3443 and $3481 \mathrm{~cm}^{-1}$ indicate the transformation of the crystalline structure from cellulose to aerocellulose. The peak at $1429 \mathrm{~cm}^{-1}$ is assigned to $\mathrm{CH}_{2}$ of the crystalline cellulose [28], and its intensity significantly decreased from cellulose to aerocelluloses, suggesting that the conversion of cellulose to aerocelluloses may result in a decrease of crystallinity. The vibration at $1315 \mathrm{~cm}^{-1}$ is due to $\mathrm{CH}_{2}$ wagging while the vibration at $1337 \mathrm{~cm}^{-1}$ is assigned to $\mathrm{C}-\mathrm{OH}$ in plane bending [29], which are characteristics of cellulose I. The decrease of the intensity of the peaks at 1315 and $1337 \mathrm{~cm}^{-1}$ for aerocelluloses further demonstrates the transition from cellulose I for cellulose to cellulose II for aerocelluloses. The intensity of the peak at $1161 \mathrm{~cm}^{-1}$ that slightly decreased in the FTIR spectra of aerocelluloses, associated with the antisymmetric bridge $\mathrm{C}_{1}-\mathrm{O}-\mathrm{C}_{4}$ stretching, is characteristic of cellulose I [30]. The intensity of

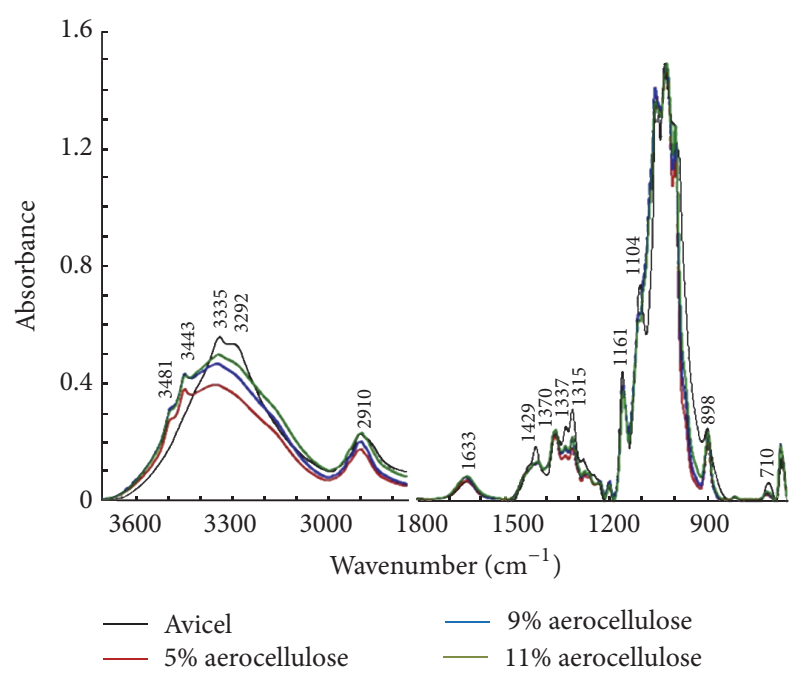

FIGURE 5: FTIR spectra of cellulose and aerocelluloses prepared from $5 \%, 9 \%$, and $11 \%$ cellulose concentrations.

the peak at $1104 \mathrm{~cm}^{-1}$ associated with the antisymmetric inplane ring stretching mode decreased in the FTIR spectra of aerocelluloses, suggesting the transformation of cellulose I to cellulose II [30]. The increase in the intensity of the peak at $898 \mathrm{~cm}^{-1}$, which is assigned to C-O-C stretching ( $\beta$-(1-4)-glycosidic linkage) for aerocelluloses, also suggests the reduction of crystallinity during the conversion from cellulose to aerocelluloses [31]. Due to the transformation of the crystalline structure from cellulose I to cellulose II, the $\mathrm{CH}_{2}$ rocking vibration located at $710 \mathrm{~cm}^{-1}$ related to crystalline cellulose $\mathrm{I}_{\beta}$ is less intense in aerocelluloses [30], which suggests a reduction in the crystallinity of aerocelluloses as compared to cellulose.

Principal Components Analysis (PCA) is applied to reduce the dimensionality of the original spectral data from 


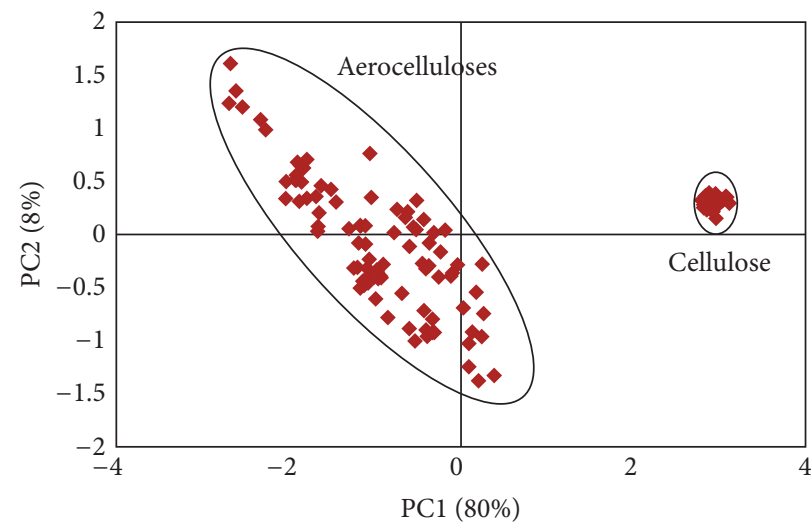

Figure 6: Principal Components Analysis (PCA) of FTIR spectra of aerocelluloses and cellulose (microcrystalline cellulose).

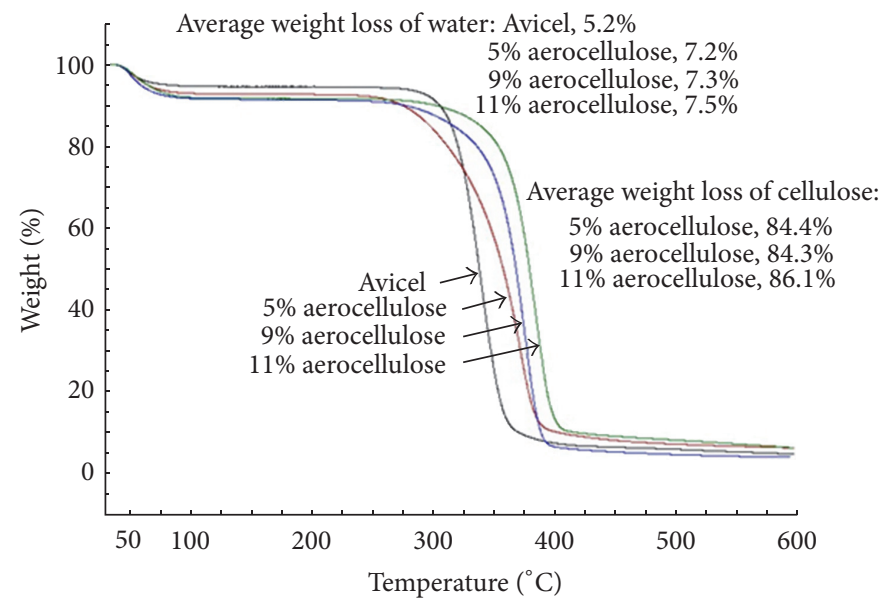

(a)

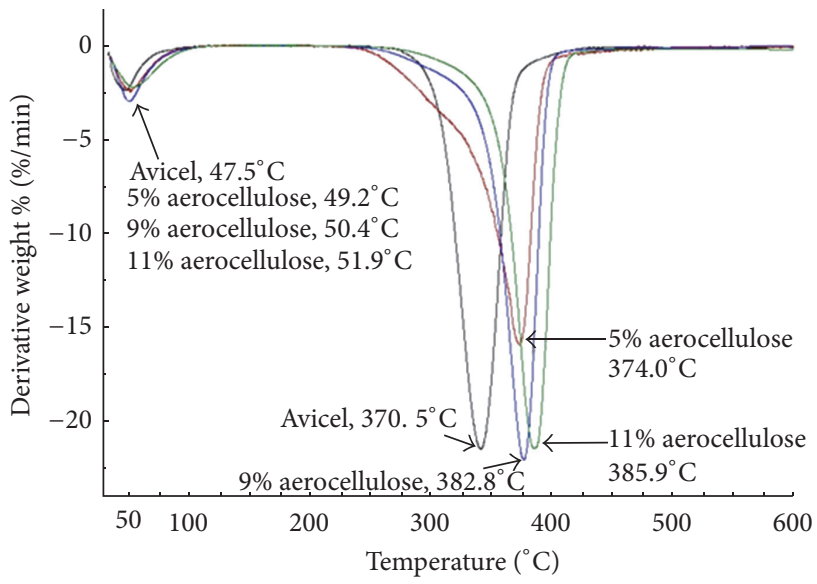

(b)

FiguRE 7: TGA curves of cellulose and aerocelluloses prepared from 5\%, 9\%, and 11\% cellulose concentrations: (a) weight loss curves; (b) derivative weight loss curves.

thousands of variables (3,350 wavenumbers) to fewer dimensions. The variability in each spectrum regarding the mean of the population presumably represents a smaller set of values (axes), termed as principal components (PCs) (Figure 6); the main sources of variability in the data are concentrated into the first two PCs (PC1 and PC2) that are plotted against each other. PC1 accounts for $80 \%$ of the variance and clearly summarizes variables of the FTIR spectra into two groups: Group 1 for aerocelluloses and Group 2 for cellulose; these two distinct categories further demonstrate the significant transformation of the crystalline structure from cellulose I for microcrystalline cellulose to cellulose II for aerocelluloses.

The thermograms in Figure 7(a) show two regions of thermal decomposition. The weight loss in region I from $37^{\circ} \mathrm{C}$ to $150^{\circ} \mathrm{C}$ is attributed to the loss of adsorbed water while the weight loss in region II from $150^{\circ} \mathrm{C}$ to $425^{\circ} \mathrm{C}$ is attributed to the decomposition of cellulose. Statistical analysis shows that the amount of adsorbed water for aerocelluloses is higher than cellulose, which suggests a higher surface area of aerocelluloses $\left(80-125 \mathrm{~m}^{2} / \mathrm{g}\right)$ than cellulose with a low surface area $\left(\sim 1 \mathrm{~m}^{2} / \mathrm{g}\right)$. The derivative weight loss curves show two major peaks of thermal decomposition (Figure 7(b)). The peak around $47^{\circ} \mathrm{C}$ is associated with maximum desorption rate of water (weight $\% / \mathrm{min}$ ) and the peak around $380^{\circ} \mathrm{C}$ is associated with the maximum decomposition rate of cellulose $[32,33]$. The water evaporation temperature at the maximum rate for cellulose is significantly lower than aerocelluloses $(p<0.05)$, suggesting that water in cellulose is easier to desorb from cellulose while porous aerocelluloses exhibited a better capability of holding water. Furthermore, the cellulose decomposition temperature at the maximum rate for cellulose is similar to aerocellulose prepared from $5 \%$ cellulose concentration while aerocelluloses prepared from $9 \%$ and $11 \%$ cellulose concentrations exhibit higher decomposition temperatures. This suggests that aerocelluloses are thermostable structure compared to cellulose.

The XRD pattern of cellulose in Figure 8 shows 4 major characteristic peaks of cellulose I at $14.9^{\circ}, 15.8^{\circ}, 22.5^{\circ}$, and $34.6^{\circ}$, which are assigned, respectively, to $1-10,110,200$, and 004 [34]. However, the peaks at $20.0^{\circ}$ and $21.6^{\circ}$ in XRD patterns of aerocelluloses show a typical cellulose II pattern. The crystalline index (CI) is calculated using the following 


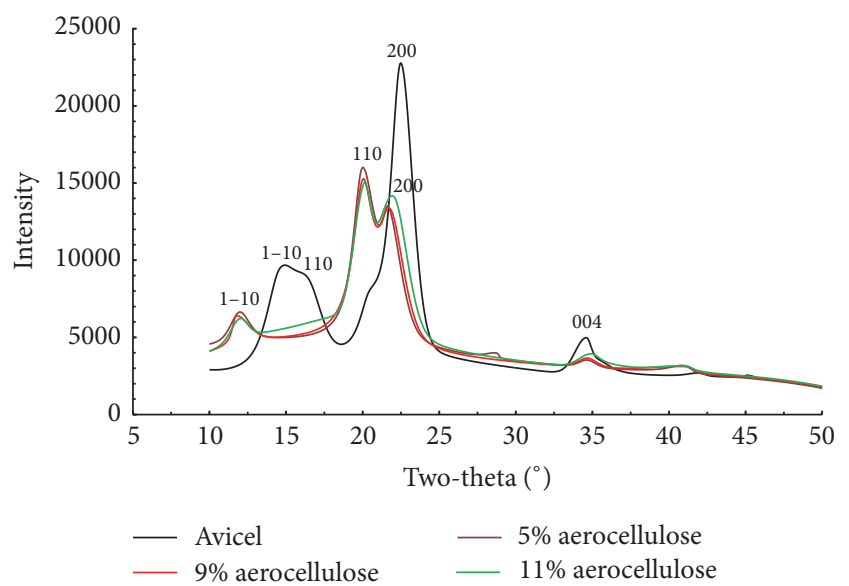

FIGURE 8: XRD patterns of cellulose and aerocelluloses prepared from $5 \%, 9 \%$, and $11 \%$ cellulose concentrations.

equation: $\mathrm{CI}=\left[\left(I_{200}-I_{\mathrm{am}}\right) / I_{200}\right] \times 100$, where $I_{200}$ is the peak intensity at $2 \theta=22.5^{\circ}$ and $I_{\mathrm{am}}$ is the intensity of the peak at $2 \theta=18^{\circ}$ [35]. It is noticed that there is a significant difference of CIs between cellulose and aerocelluloses $(p<0.05)$. These results are consistent with FTIR analysis above.

3.2. Cationic Functionalization of Aerocelluloses. Cationic functionalization of aerocelluloses was successfully achieved using cationic reagent (CHPTAC) as shown in Scheme 1. The resulting cationized aerocelluloses are expected to remove the anionic dye (CI RB19) from wastewater due to the presence of a large number of positively charged sites (quaternary ammonium cations) on the surface of the aerocelluloses. As shown in Figure 9, the peak around $1500 \mathrm{~cm}^{-1}$, associated with quaternary ammonium cation in the FTIR spectrum of the cationized aerocellulose, indicates the presence of CHPTAC on aerocellulose $[28,36]$. Figure 10 shows the variation of the dye concentration as a function of time in DI water containing CI RB 19 dye using cationized aerocelluloses prepared at $5 \%$ and $11 \%$ cellulose concentrations. Regardless of the cellulose concentration used, the cationized aerocelluloses exhibit strong ability to remove dye molecules. This is illustrated by the drastic decrease of the dye concentration in solution until the complete removal on day 6 (Figure 11(e)). The aerocellulose without cationic functionalization only absorbs a limited amount of dye as shown in Figure 11(b). The cationic functionalization of aerocellulose immobilizes negatively charged dye on positively charged sites, while aerocellulose with porous morphology may absorb limited amount of dyes only. As shown in Figures 11(b) and 11(d), no difference in the appearance of aerocellulose and cationized aerocellulose is present, suggesting that the cationic functionalization of aerocellulose does not impact the surface area and pore volume of aerocelluloses due to the steric effect resulting from positively charged quaternary ammonium molecules grafted onto the aerocellulose [37]. Therefore, cationic functionalization and good porosity enable aerocelluloses to exhibit excellent removal of negatively charged dye molecules form wastewater.

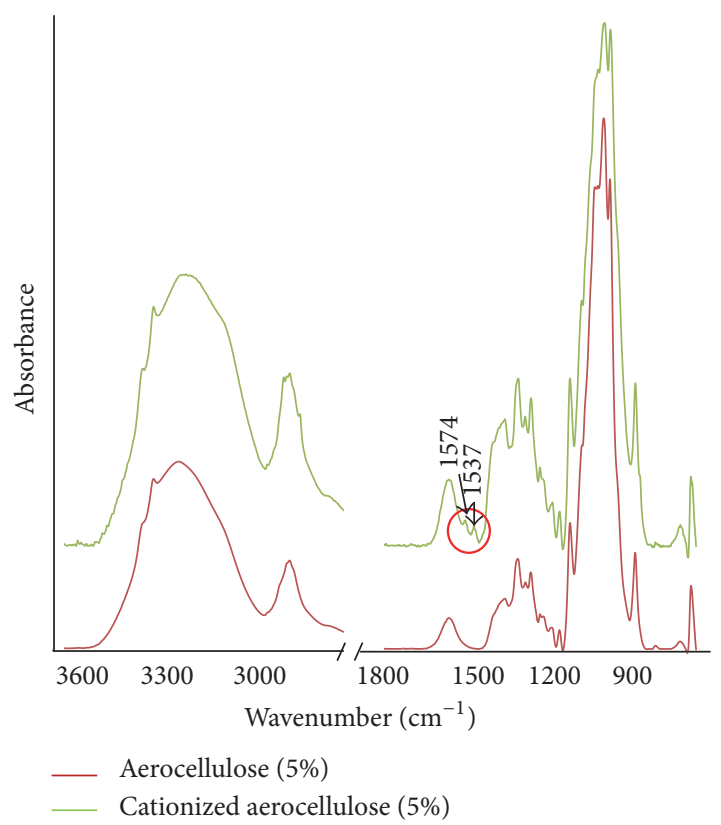

FIGURE 9: FTIR spectra of aerocellulose and cationized aerocellulose prepared from $5 \%$ cellulose concentration.

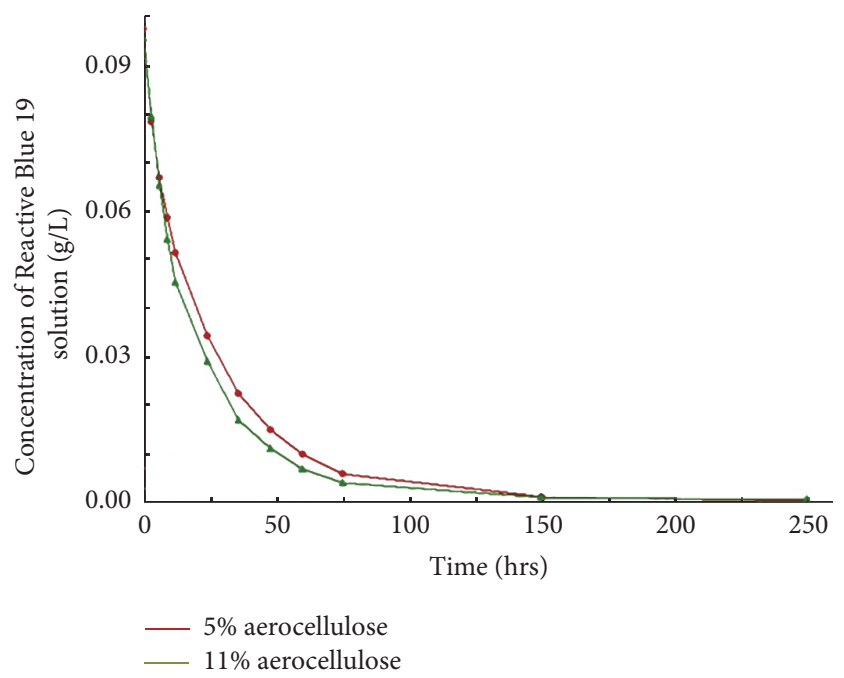

FIGURE 10: Changes in dye concentration of reactive dye (CI RB19) in the water as a function of time using cationized aerocelluloses prepared from $5 \%$ and $11 \%$ cellulose concentrations.

\section{Conclusions}

In this study, microcrystalline cellulose was dissolved in $\mathrm{NaOH} /$ water solvent system followed by gelation and supercritical drying operations to prepare aerocelluloses. The aerocelluloses prepared from different cellulose concentrations exhibited a porous structure and a specific surface area of 80 $125 \mathrm{~m}^{2} / \mathrm{g}$. FTIR and XRD analyses indicated typical transformation of crystalline structure from cellulose I (cellulose) to cellulose II (aerocelluloses). Aerocelluloses were cationically functionalized and the resulting material exhibited a strong ability to completely remove negatively charged dyes from 


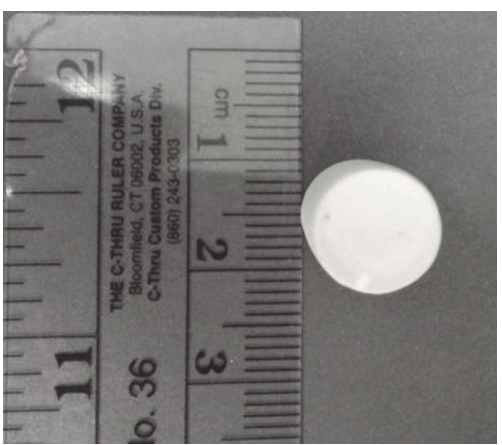

(a)

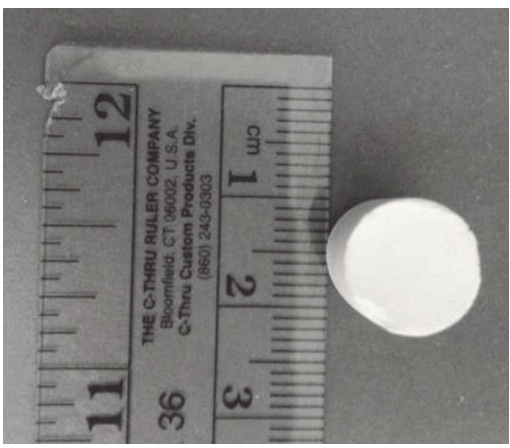

(c)

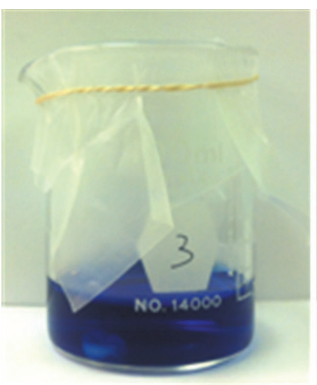

(e) $0 \mathrm{~h}$
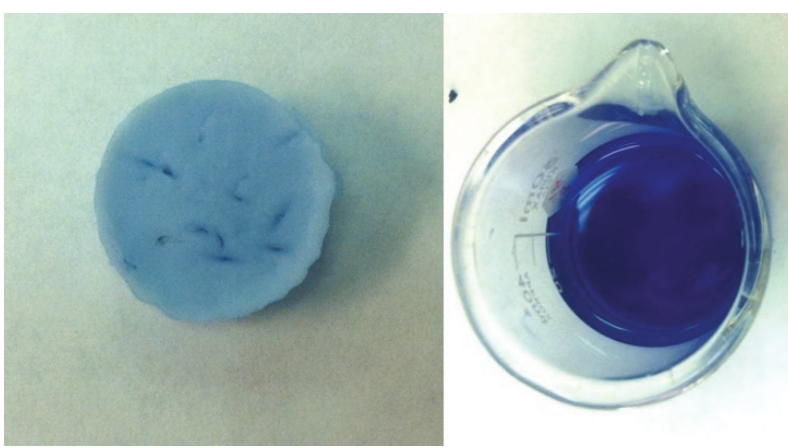

(b)

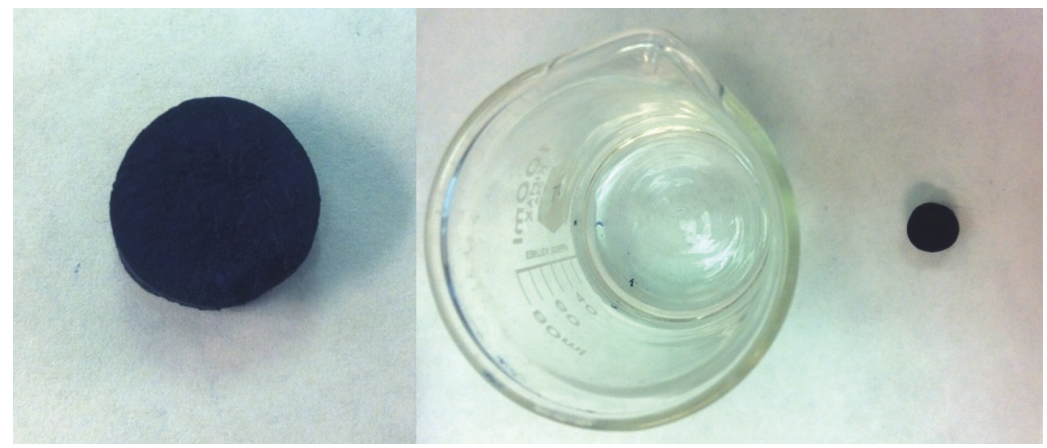

(d)

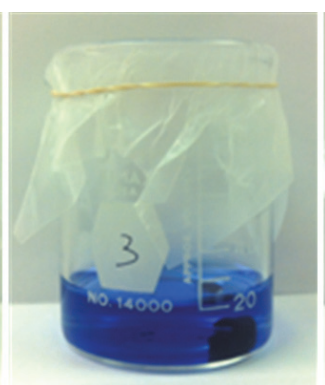

(e) $24 \mathrm{~h}$

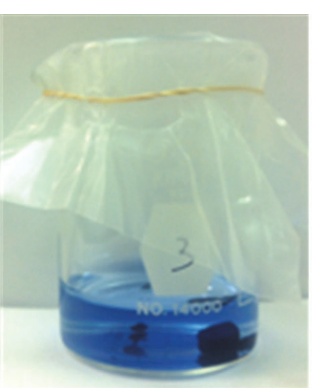

(e) $48 \mathrm{~h}$

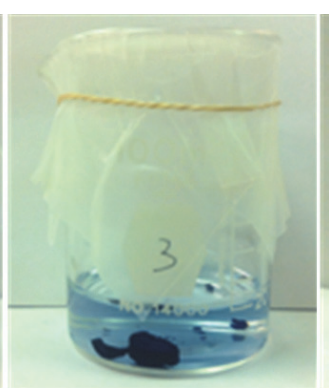

(e) $75 \mathrm{~h}$

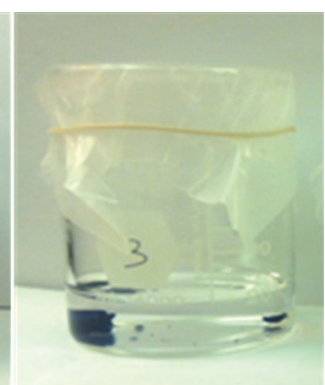

(e) $150 \mathrm{~h}$

FIgURE 11: Comparison of the removal efficiency of reactive dye (CI RB19) from the water for aerocellulose and cationized aerocellulose prepared from 5\% cellulose concentration: (a) aerocellulose and (c) cationized aerocellulose before dye absorption; (b) aerocellulose and (d) cationic aerocellulose after dye absorption; (e) photographs of the dye fixation over time for cationized aerocellulose.

water. In the light of sustainability, biodegradability, and low cost of cellulose, highly porous aerocelluloses prepared in this study could be a promising material as a fast absorbent to clean environmental pollutants.

\section{Competing Interests}

The authors declare that there are no competing interests regarding the publication of this paper.

\section{Acknowledgments}

The authors would like to thank Texas Department of Agriculture and Texas Tech University for partial financial support for this project, Tech University manuscript number T-4-706.

\section{References}

[1] N. Hüsing and U. Schubert, "Aerogele-luftige materialien: chemie, struktur und eigenschaften," Angewandte Chemie, vol. 110, no. 1-2, pp. 22-47, 1998.

[2] S. J. Teichner, G. A. Nicolaon, M. A. Vicarini, and G. E. E. Gardes, "Inorganic oxide aerogels," Advances in Colloid and Interface Science, vol. 5, no. 3, pp. 245-273, 1976.

[3] A. Soleimani Dorcheh and M. H. Abbasi, "Silica aerogel; synthesis, properties and characterization," Journal of Materials Processing Technology, vol. 199, no. 1, pp. 10-26, 2008.

[4] A. Cannavale, F. Fiorito, M. Manca, G. Tortorici, R. Cingolani, and G. Gigli, "Multifunctional bioinspired sol-gel coatings for architectural glasses," Building and Environment, vol. 45, no. 5, pp. 1233-1243, 2010.

[5] J. L. Gurav, A. V. Rao, D. Y. Nadargi, and H.-H. Park, "Ambient pressure dried TEOS-based silica aerogels: good absorbents of 
organic liquids," Journal of Materials Science, vol. 45, no. 2, pp. 503-510, 2010.

[6] T. Mehling, I. Smirnova, U. Guenther, and R. H. H. Neubert, "Polysaccharide-based aerogels as drug carriers," Journal of Non-Crystalline Solids, vol. 355, no. 50-51, pp. 2472-2479, 2009.

[7] D. L. Plata, Y. J. Briones, R. L. Wolfe et al., "Aerogel-platform optical sensors for oxygen gas," Journal of Non-Crystalline Solids, vol. 350, pp. 326-335, 2004.

[8] S. L. Lee, H. Nur, and H. Hamdan, "Physical properties and bifunctional catalytic performance of phosphate-vanadium impregnated silica-titania aerogel," Catalysis Letters, vol. 132, no. 1-2, pp. 28-33, 2009.

[9] S. White, J. Demko, and A. Tomich, "Flexible aerogel as a superior thermal insulation for high temperature superconductor cable applications," in Proceedings of the Joint Cryogenic Engineering and International Cryogenic Materials Conferences, pp. 788-795, Tucson, Ariz, USA, July 2009.

[10] D. Klemm, B. Heublein, H.-P. Fink, and A. Bohn, "Cellulose: fascinating biopolymer and sustainable raw material," Angewandte Chemie - International Edition, vol. 44, no. 22, pp. 33583393, 2005.

[11] Y. Hu and J. M. Catchmark, "Formation and characterization of spherelike bacterial cellulose particles produced by acetobacter xylinum JCM 9730 strain," Biomacromolecules, vol. 11, no. 7, pp. 1727-1734, 2010.

[12] F. Fischer, A. Rigacci, R. Pirard, S. Berthon-Fabry, and P. Achard, "Cellulose-based aerogels," Polymer, vol. 47, no. 22, pp. 76367645, 2006.

[13] C. Tan, B. M. Fung, J. K. Newman, and C. Vu, "Organic aerogels with very high impact strength," Advanced Materials, vol. 13, no. 9, pp. 644-646, 2001.

[14] H. Jin, Y. Nishiyama, M. Wada, and S. Kuga, "Nanofibrillar cellulose aerogels," Colloids and Surfaces A: Physicochemical and Engineering Aspects, vol. 240, no. 1-3, pp. 63-67, 2004.

[15] J. Innerlohinger, H. K. Weber, and G. Kraft, "Aerocellulose: aerogels and aerogel-like materials made from cellulose," in Macromolecular Symposia, vol. 244, pp. 126-135, Wiley, Hoboken, NJ, USA, 2006.

[16] R. Gavillon and T. Budtova, "Aerocellulose: new highly porous cellulose prepared from cellulose- $\mathrm{NaOH}$ aqueous solutions," Biomacromolecules, vol. 9, no. 1, pp. 269-277, 2008.

[17] S. Hoepfner, L. Ratke, and B. Milow, "Synthesis and characterisation of nanofibrillar cellulose aerogels," Cellulose, vol. 15, no. 1, pp. 121-129, 2008.

[18] B. J. C. Duchemin, M. P. Staiger, N. Tucker, and R. H. Newman, "Aerocellulose based on all-cellulose composites," Journal of Applied Polymer Science, vol. 115, no. 1, pp. 216-221, 2010.

[19] X. Chang, D. Chen, and X. Jiao, "Starch-derived carbon aerogels with high-performance for sorption of cationic dyes," Polymer, vol. 51, no. 16, pp. 3801-3807, 2010.

[20] E. Forgacs, T. Cserháti, and G. Oros, "Removal of synthetic dyes from wastewaters: a review," Environment International, vol. 30, no. 7, pp. 953-971, 2004.

[21] N. Tonanon, Y. Wareenin, A. Siyasukh et al., "Preparation of resorcinol formaldehyde (RF) carbon gels: use of ultrasonic irradiation followed by microwave drying," Journal of NonCrystalline Solids, vol. 352, no. 52-54, pp. 5683-5686, 2006.

[22] M. Vakili, M. Rafatullah, B. Salamatinia et al., "Application of chitosan and its derivatives as adsorbents for dye removal from water and wastewater: a review," Carbohydrate Polymers, vol. 113, pp. 115-130, 2014.
[23] A. Grosman and C. Ortega, "Nature of capillary condensation and evaporation processes in ordered porous materials," Langmuir, vol. 21, no. 23, pp. 10515-10521, 2005.

[24] G. Leofanti, M. Padovan, G. Tozzola, and B. Venturelli, "Surface area and pore texture of catalysts," Catalysis Today, vol. 41, no. 1-3, pp. 207-219, 1998.

[25] A. Balamurugan, G. Balossier, D. Laurent-Maquin et al., "An in vitro biological and anti-bacterial study on a sol-gel derived silver-incorporated bioglass system," Dental Materials, vol. 24, no. 10, pp. 1343-1351, 2008.

[26] S. Y. Oh, D. I. Yoo, Y. Shin, and G. Seo, "FTIR analysis of cellulose treated with sodium hydroxide and carbon dioxide," Carbohydrate Research, vol. 340, no. 3, pp. 417-428, 2005.

[27] M. Schwanninger, J. C. Rodrigues, H. Pereira, and B. Hinterstoisser, "Effects of short-time vibratory ball milling on the shape of FT-IR spectra of wood and cellulose," Vibrational Spectroscopy, vol. 36, no. 1, pp. 23-40, 2004.

[28] N. Abidi, L. Cabrales, and C. H. Haigler, "Changes in the cell wall and cellulose content of developing cotton fibers investigated by FTIR spectroscopy," Carbohydrate Polymers, vol. 100, pp. 9-16, 2014.

[29] X. Colom and F. Carrillo, "Crystallinity changes in lyocell and viscose-type fibres by caustic treatment," European Polymer Journal, vol. 38, no. 11, pp. 2225-2230, 2002.

[30] N. Abidi, L. Cabrales, and E. Hequet, "Fourier transform infrared spectroscopic approach to the study of the secondary cell wall development in cotton fiber," Cellulose, vol. 17, no. 2, pp. 309-320, 2010.

[31] N. Abidi, E. Hequet, L. Cabrales, J. Gannaway, T. Wilkins, and L. W. Wells, "Evaluating cell wall structure and composition of developing cotton fibers using fourier transform infrared spectroscopy and thermogravimetric analysis," Journal of Applied Polymer Science, vol. 107, no. 1, pp. 476-486, 2008.

[32] H. Yang, R. Yan, H. Chen, D. H. Lee, and C. Zheng, "Characteristics of hemicellulose, cellulose and lignin pyrolysis," Fuel, vol. 86, no. 12-13, pp. 1781-1788, 2007.

[33] L. Burhenne, J. Messmer, T. Aicher, and M.-P. Laborie, "The effect of the biomass components lignin, cellulose and hemicellulose on TGA and fixed bed pyrolysis," Journal of Analytical and Applied Pyrolysis, vol. 101, pp. 177-184, 2013.

[34] J. Gu, J. M. Catchmark, E. Q. Kaiser, and D. D. Archibald, "Quantification of cellulose nanowhiskers sulfate esterification levels," Carbohydrate Polymers, vol. 92, no. 2, pp. 1809-1816, 2013.

[35] Y. Hu, J. M. Catchmark, Y. Zhu et al., "Engineering of porous bacterial cellulose toward human fibroblasts ingrowth for tissue engineering," Journal of Materials Research, vol. 29, no. 22, pp. 2682-2693, 2014.

[36] M. Kozak and L. Domka, "Adsorption of the quaternary ammonium salts on montmorillonite," Journal of Physics and Chemistry of Solids, vol. 65, no. 2-3, pp. 441-445, 2004.

[37] W. Shi, H. Gu, X. Chen, Y. Huang, W. Wu, and J. Wang, "Adsorption of chlorinated acetic acids by quaternary ammonium cationic cellulose," Water Science and Technology: Water Supply, vol. 14, no. 2, pp. 321-328, 2014. 

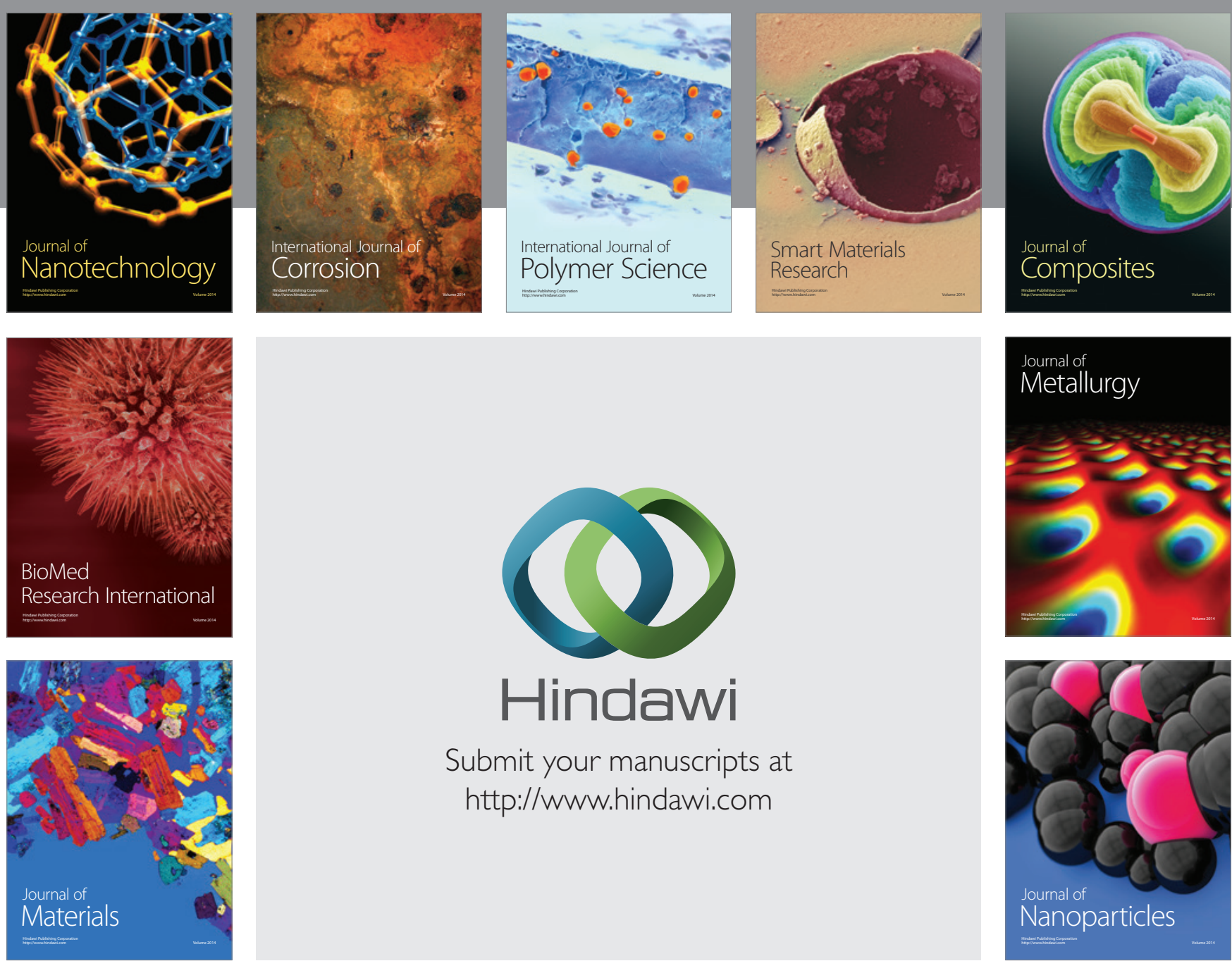

\section{Hindawi}

Submit your manuscripts at

http://www.hindawi.com

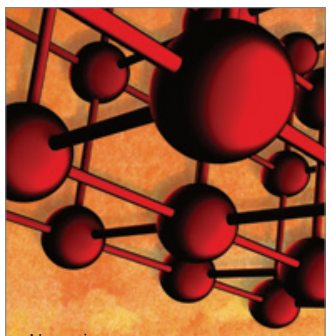

Materials Science and Engineering
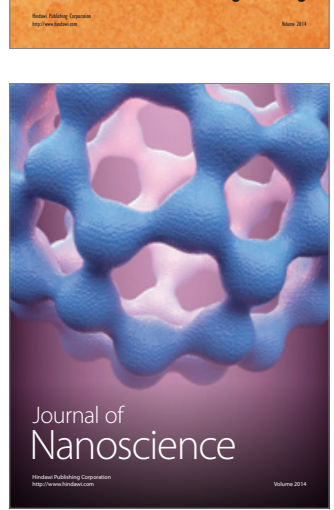
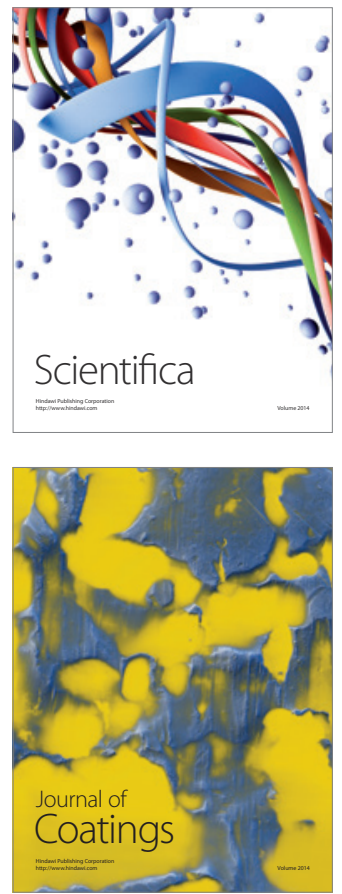
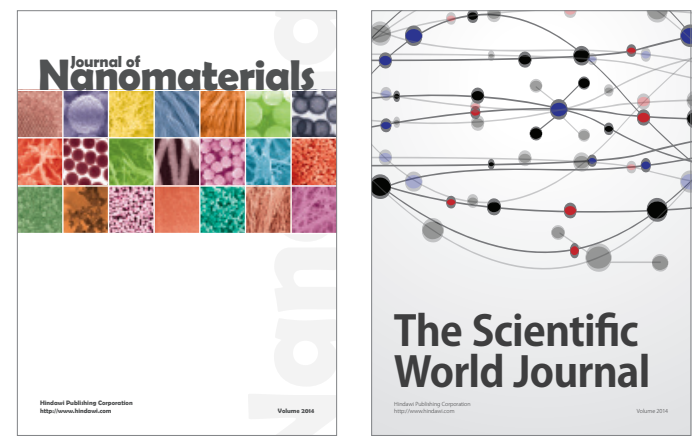

The Scientific World Journal
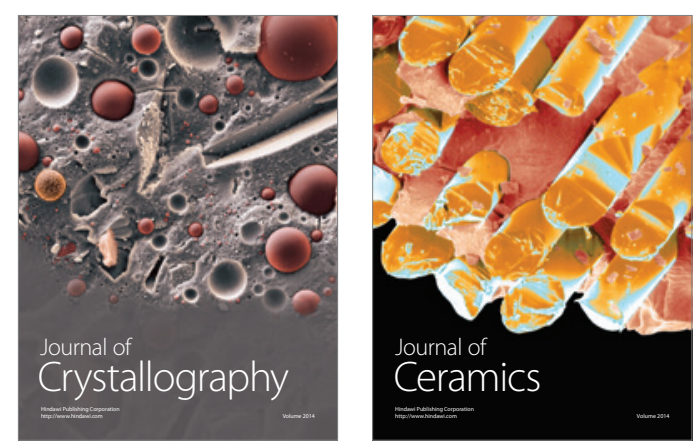
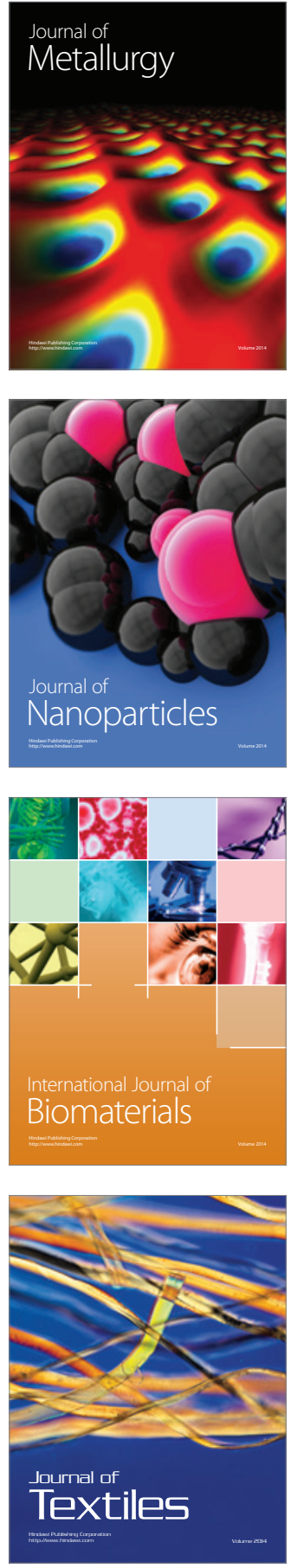